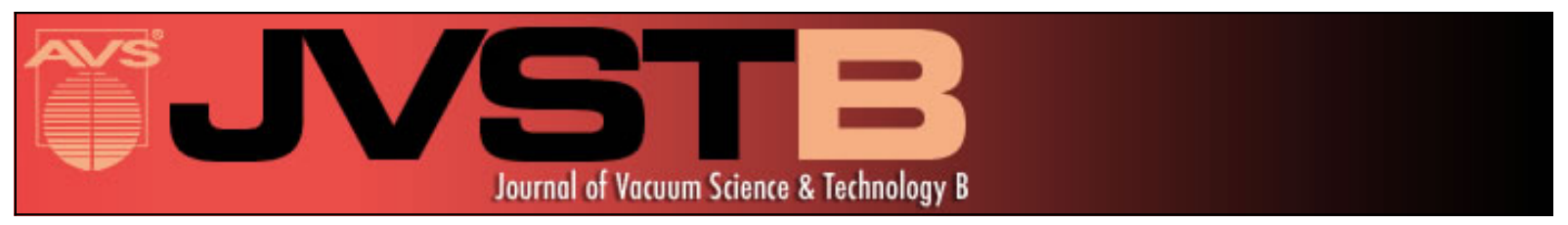

\title{
Structural properties of InAs/InAs1-xSbx type-II superlattices grown by molecular beam epitaxy
}

Lu Ouyang, Elizabeth H. Steenbergen, Yong-Hang Zhang, Kalyan Nunna, Diana L. Huffaker, and David J. Smith

Citation: Journal of Vacuum Science \& Technology B 30, 02B106 (2012); doi: 10.1116/1.3672026

View online: http://dx.doi.org/10.1116/1.3672026

View Table of Contents: http://scitation.aip.org/content/avs/journal/jvstb/30/2?ver=pdfcov

Published by the AVS: Science \& Technology of Materials, Interfaces, and Processing

\section{Articles you may be interested in}

Molecular beam epitaxy using bismuth as a constituent in InAs and a surfactant in InAs/lnAsSb superlattices J. Vac. Sci. Technol. B 32, 02C120 (2014); 10.1116/1.4868111

Impact of substrate temperature on the structural and optical properties of strain-balanced InAs/InAsSb type-II superlattices grown by molecular beam epitaxy

Appl. Phys. Lett. 102, 071903 (2013); 10.1063/1.4793231

Strain-balanced InAs/InAs1-xSbx type-II superlattices grown by molecular beam epitaxy on GaSb substrates J. Vac. Sci. Technol. B 30, 02B107 (2012); 10.1116/1.3672028

Structural and optical characterization of type-II InAs/InAs1-xSbx superlattices grown by metalorganic chemical vapor deposition

Appl. Phys. Lett. 99, 071111 (2011); 10.1063/1.3625429

Type-II In As/Ga Sb superlattices grown on GaSb (311)B by molecular beam epitaxy for long-wavelength infrared applications

J. Vac. Sci. Technol. B 24, 2144 (2006); 10.1116/1.2214705

\section{$\bigoplus$ SHIMADZU Powerful, Multi-functional UV-Vis-NIR and Excellence in Science FTIR Spectrophotometers}

Providing the utmost in sensitivity, accuracy and resolution for applications in materials characterization and nano research

- Photovoltaics

- Polymers

- Thin films

- Paints

- Ceramics

- DNA film structures

- Coatings

- Packaging materials
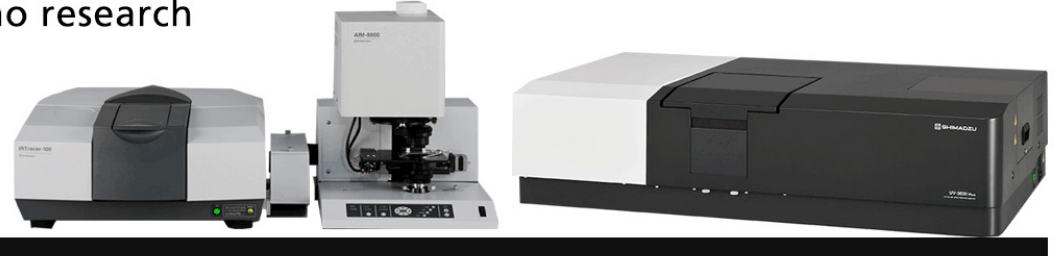


\title{
Structural properties of $\operatorname{InAs} / \ln A s_{1-x} S_{b_{x}}$ type-II superlattices grown by molecular beam epitaxy
}

\author{
Lu Ouyang ${ }^{\text {a) }}$ \\ Department of Physics, Arizona State University, Tempe, Arizona 85287
}

Elizabeth H. Steenbergen and Yong-Hang Zhang

School of Electrical, Computer and Energy Engineering and Center for Photonics Innovation, Arizona State

University, Tempe, Arizona 85287

Kalyan Nunna and Diana L. Huffaker

California NanoSystems Institute, University of California, Los Angeles, California 90095

David J. Smith

Department of Physics and Center for Photonics Innovation, Arizona State University, Tempe, Arizona 85287

(Received 20 September 2011; accepted 3 December 2011; published 21 December 2011)

\begin{abstract}
Strain-balanced InAs/InAs ${ }_{1-x} S_{x}$ type-II superlattices (SLs) have been proposed for possible longwavelength infrared applications. This paper reports a detailed structural characterization study of $\mathrm{InAs} / \mathrm{InAs}_{1-\mathrm{x}} \mathrm{Sb}_{\mathrm{x}} \mathrm{SLs}$ with varied $\mathrm{Sb}$ composition grown on $\mathrm{GaSb}(001)$ substrates by modulated and conventional molecular beam epitaxy (MBE). X-ray diffraction was used to determine the SL periods and the average composition of the $\operatorname{InAs}_{1-\mathrm{X}} \mathrm{Sb}_{\mathrm{x}}$ alloy layers. Cross-section transmission electron micrographs revealed the separate $\operatorname{In}(\mathrm{As}) \mathrm{Sb} / \mathrm{InAs}(\mathrm{Sb})$ ordered-alloy layers within individual InAs ${ }_{1-x} \mathrm{Sb}_{\mathrm{x}}$ layers for SLs grown by modulated MBE. For the SLs grown by conventional MBE, examination by high-resolution electron microscopy revealed that interfaces for $\operatorname{InAs} s_{1-x} \mathrm{Sb}_{\mathrm{x}}$ deposited on InAs were more abrupt, relative to InAs deposited on $\operatorname{InAs}{ }_{1-x} \mathrm{Sb}_{\mathrm{x}}$ : this feature was attributed to $\mathrm{Sb}$ surfactant segregation occurring during the SL growth. Overall, these results establish that strain-balanced SL structures with excellent crystallinity can be achieved with proper design (well thickness versus Sb composition) and suitably optimized growth conditions. (C) 2012 American Vacuum Society. [DOI: 10.1116/1.3672026]
\end{abstract}

\section{INTRODUCTION}

Type-II superlattices (SLs) have attracted much interest from the semiconductor industry since first being proposed. ${ }^{1}$ Antimonide-based type-II SLs have been recognized as possible low-cost alternatives to the $\mathrm{HgCdTe}$ materials system for infrared (IR) applications, due to several key advantages including lower tunneling current, ${ }^{2}$ greater flexibility in bandgap engineering, ${ }^{3}$ and reduced Auger recombination. ${ }^{3}$ Extensive investigations of InAs/(In)GaSb type-II SLs have been carried out, including theoretical calculations of the band structure ${ }^{4}$ and minority carrier lifetimes, ${ }^{5}$ and significant success has been achieved for device performance in mid-, long- and very-long-wavelength infrared (VLWIR) ranges. ${ }^{6-9}$ Strain-balanced InAs/InAs ${ }_{1-x} \mathrm{Sb}_{\mathrm{x}}$ SLs have been proposed as another possible alternative to $\mathrm{HgCdTe},{ }^{10}$ and have already shown great promise for mid-IR laser and photodetector structures ${ }^{11}$ with photoluminescence emission in the range of 5-10 $\mu \mathrm{m}$ being achieved for SL structures containing $\mathrm{Sb}$ concentrations of $14-27 \% .^{12}$ Recently, InAs/ $\mathrm{InAs}_{1-\mathrm{x}} \mathrm{Sb}_{\mathrm{x}} \mathrm{SLs}$ grown by metalorganic chemical vapor depostition (MOCVD) have been studied in more detail: these SLs showed excellent structural properties and strong optical response. ${ }^{13,14}$ The absence of gallium in these InAs/ $\mathrm{InAs}_{1-\mathrm{x}} \mathrm{Sb}_{\mathrm{x}} \mathrm{SLs}$ is expected to simplify the SL interfaces and

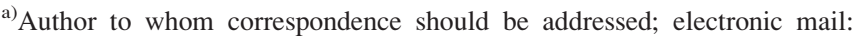
louyang@asu.edu
}

hence the growth process, ${ }^{13}$ and also result in longer carrier lifetimes, ${ }^{15,16}$ as very recently demonstrated. ${ }^{17}$

In the growth of mixed $\mathrm{As} / \mathrm{Sb}$ alloys by conventional solid-source molecular beam epitaxy (MBE), the $\mathrm{As}_{2}$ and $\mathrm{Sb}_{2}$ beam flux ratio is normally used to control the average group- $\mathrm{V}$ composition of the epitaxial material. However, due to large differences in the incorporation coefficients of $\mathrm{As}_{2}$ and $\mathrm{Sb}_{2}$, accurate control of composition in the $\mathrm{InAs}_{1-\mathrm{x}} \mathrm{Sb}_{\mathrm{x}}$ alloys becomes challenging. Growth by modulated MBE involves control of As and $\mathrm{Sb}$ incorporation by rapidly alternating the $\mathrm{As}_{2}$ and $\mathrm{Sb}_{2}$ beam flux, using the timing of shutter operation to control the group- $\mathrm{V}$ composition. ${ }^{18}$ This growth technique could possibly provide more precise control and reproducibility of the group- $\mathrm{V}$ alloy composition in the $\operatorname{InAs}_{1-x} \mathrm{Sb}_{\mathrm{x}}$ layers of InAs/InAs $\mathrm{I}_{1-\mathrm{x}} \mathrm{Sb}_{\mathrm{x}}$ SLs. Improvements in composition control and crystalline quality of $\mathrm{AlAs}_{\mathrm{x}} \mathrm{Sb}_{1-\mathrm{x}}$ and $\mathrm{In}(\mathrm{Ga}) \mathrm{As}_{\mathrm{x}} \mathrm{Sb}_{1-\mathrm{x}}$ alloys grown by modulated MBE have been reported. ${ }^{11,19-23}$ Further advantages of modulated MBE are that the technique could provide protection against composition drift and achieve more abrupt interfaces, ${ }^{23}$ which are important factors to take into consideration since the transition wavelength and recombination efficiency are expected to be strongly influenced by the compositional abruptness at the interfaces. ${ }^{24,25}$

High quality InAs/InAs ${ }_{1-x} \mathrm{Sb}_{\mathrm{x}}$ SLs require sharp and defect-free interfaces between InAs and $\operatorname{InAs}_{1-x} \mathrm{Sb}_{\mathrm{x}}$ layers. In this study, strain-balanced InAs/InAs ${ }_{1-x} S_{b_{x}}$ type-II SLs on $\mathrm{GaSb}$ (001) substrates with different Sb compositions, but 


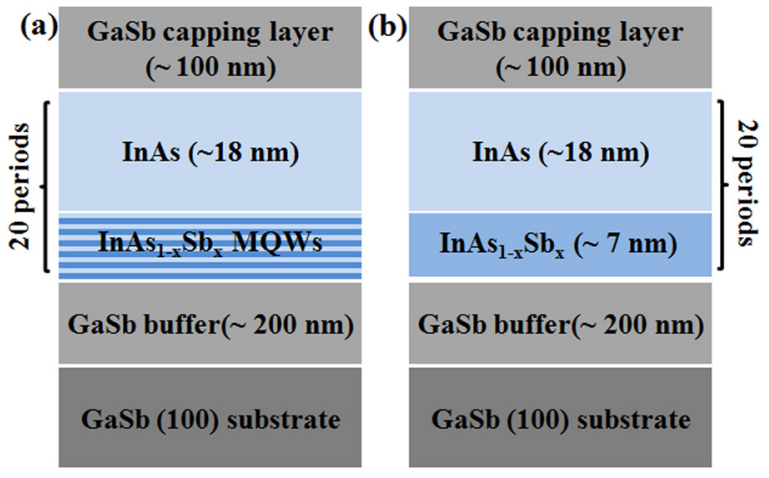

FIG. 1. (Color online) Schematic illustration of the $\operatorname{InAs} / \operatorname{InAs}_{1-x} \mathrm{Sb}_{\mathrm{x}} \mathrm{SL}$ structure design for: (a) ordered-alloy and (b) random alloy.

the same layer thicknesses, were designed for LWIR detectors of different wavelengths. Transmission electron microscopy (TEM) was used to investigate the microstructure of InAs/InAs ${ }_{1-x} \mathrm{Sb}_{\mathrm{x}}$ SLs with ordered and random $\mathrm{InAs}_{1-\mathrm{x}} \mathrm{Sb}_{\mathrm{x}}$ alloy layers grown by modulated and conventional MBE, respectively. $\mathrm{X}$-ray diffraction (XRD) was used to determine the average composition of the $\operatorname{InAs}_{1-\mathrm{x}} \mathrm{Sb}_{\mathrm{x}}$ alloy layers and the SL periods. Further information including details of the SL structure design and measurements of the optical properties of these samples is being reported elsewhere. ${ }^{26}$

\section{EXPERIMENTAL DETAILS}

The SL samples were grown in a solid-source MBE system, using modulated and conventional MBE growth techniques. All samples nominally consisted of a $0.2-\mu$ m-thick GaSb buffer layer grown on an $n$-type GaSb (001) substrate at $500{ }^{\circ} \mathrm{C}$, followed by deposition of 7-nm-thick InAs ${ }_{1-\mathrm{x}} \mathrm{Sb}_{\mathrm{x}}$ layers alternating with 18-nm-thick InAs layers for 20 periods, at a growth temperature of $435^{\circ} \mathrm{C}$. Finally, a $0.1-\mu \mathrm{m}-$ thick GaSb capping layer was deposited at $480^{\circ} \mathrm{C}$. Figure 1 shows a schematic of the sample structures. The modulated and conventional MBE growths are expected to yield ordered and random $\mathrm{InAs}_{1-\mathrm{x}} \mathrm{Sb}_{\mathrm{x}}$ alloy layers, respectively.

For the modulated MBE growth, the In shutter was kept open throughout the entire period of growth of the $\mathrm{InAs}_{1-\mathrm{x}} \mathrm{Sb}_{\mathrm{x}}$ layers, while the As and $\mathrm{Sb}$ shutters were alternately opened and closed for very short periods. The overall $\mathrm{Sb}$ composition would then be controlled by the Sb-shutter duty-cycle: $\mathrm{Sb}_{\text {shutter-time }} /\left(\mathrm{As}_{\text {shutter-time }}+\mathrm{Sb}_{\text {shutter-time }}\right)$. Each of these ordered $\mathrm{InAs}_{1-\mathrm{x}} \mathrm{Sb}_{\mathrm{x}}$ alloy layers consisted of sixperiod $\operatorname{In}(\mathrm{As}) \mathrm{Sb} / \mathrm{InAs}(\mathrm{Sb})$ multiple quantum well (MQW) layers. The relevant growth parameters are listed in Table I.

The high-resolution XRD measurements were performed using a PANalytical X'pert Pro MRD, and the average Sb compositions of the $\operatorname{InAs}_{1-\mathrm{x}} \mathrm{Sb}_{\mathrm{x}}$ alloys were determined by comparing simulations to (004) high-resolution XRD measurements. Cross-sectional specimens were prepared for TEM observation using mechanical polishing and dimpling followed by argon ion-milling. The mechanical polishing and dimpling typically reduced the sample thicknesses to $10 \sim 12 \mu \mathrm{m}$, and small holes in the films were then made by ion-milling at low energy $(2.5 \sim 3 \mathrm{keV})$, using a liquid-nitrogen-temperature cooling stage to minimize any thermal or ion-beam damage. ${ }^{27}$ The TEM characterization studies were mostly carried out using a JEM-4000EX high-resolution electron microscope operated at $400 \mathrm{keV}$ and with a structural resolution of $\sim 1.7 \AA$. All samples were prepared for observation along $\{110\}$-type zone-axis projections so that the direction of the electron beam would be aligned perpendicular to the growth surface normal.

\section{RESULTS AND DISCUSSTION}

The InAs/InAs ${ }_{1-\mathrm{x}} \mathrm{Sb}_{\mathrm{x}}$ SLs samples that are described in this paper, which include two ordered alloy SLs and two random alloy SLs, are summarized in Table I. The SL periods and the average $\mathrm{Sb}$ compositions of the two random $\mathrm{InAs}_{1-\mathrm{x}} \mathrm{Sb}_{\mathrm{x}}$ alloy samples, as determined by high-resolution XRD measurements are also listed. The XRD patterns of Samples A and B are shown in Fig. 2, together with the corresponding simulations offset below each experimental profile. The most intense SL peak for Sample A no longer corresponds to the zero-order peak because of the large SL period. The XRD of the thick individual $\mathrm{InAs}_{1-\mathrm{x}} \mathrm{Sb}_{\mathrm{x}}$ and InAs layers show the envelope modulation of the SL peaks on either side of the substrate peak, causing some satellite peaks to be more intense than the zero-order SL peak. From the separation of the substrate peak from the zero-order SL peak, the average SL strain in the growth direction is determined to be $0.18 \%$ for Sample A. In comparison, Sample B has broader peaks than Sample A, suggesting the presence of increased defect density, which was later confirmed in the TEM microstructure studies.

Cross-sectional electron micrographs of Sample A, as for example shown in Fig. 3, revealed excellent crystallinity and a very low density of growth defects, and indicated an SL periodicity of $245 \AA$, which was in close agreement with the results of the XRD simulation. Higher magnification images of the SL, such as Fig. 4, showed sharp interfaces between the individual $\mathrm{InAs}_{1-\mathrm{x}} \mathrm{Sb}_{\mathrm{x}}$ and InAs layers, and interfacial misfit dislocations were not observed. Moreover, the ordered-alloy structure, consisting of six-period $\mathrm{In}(\mathrm{As}) \mathrm{Sb} /$ $\mathrm{InAs}(\mathrm{Sb}) \mathrm{MQW}$ layers, is clearly visible within each

TABLE I. Summary of SL samples reported in this investigation.

\begin{tabular}{|c|c|c|c|c|c|c|}
\hline Sample & MBE growth & Sb shutter-time (second) & Sb shutter duty-cycle & Flux ratio $\mathrm{Sb} /(\mathrm{Sb}+\mathrm{As})$ & SL period $(\mathrm{nm})$ & $\mathrm{x}_{\mathrm{sb}}$ \\
\hline $\mathbf{A}$ & Modulated & 3 & $35 \%$ & - & 24.5 & - \\
\hline B & Modulated & 4 & $47 \%$ & - & 24.1 & - \\
\hline $\mathrm{C}$ & Conventional & - & - & 0.35 & 24.6 & 0.28 \\
\hline D & Conventional & - & - & 0.37 & 24.6 & 0.29 \\
\hline
\end{tabular}




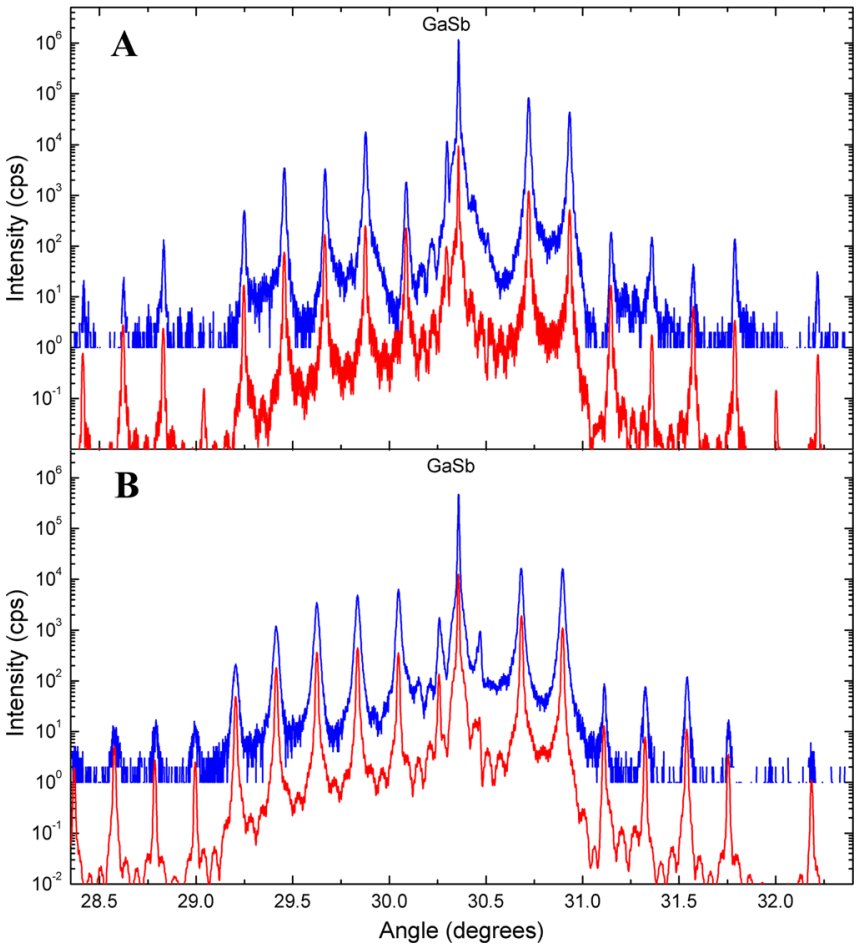

FIG. 2. (Color online) High-resolution XRD (004) $\omega-2 \theta$ profiles and corresponding simulations (offset below each measurement) for Samples A and B,

$\operatorname{InAs}_{1-\mathrm{x}} \mathrm{Sb}_{\mathrm{x}}$ layer. These layers are very well defined, with the darker lines corresponding to the $\operatorname{In}($ As)Sb layers.

In the case of Sample B, which is another SL sample grown by modulated MBE when the growth conditions were not yet fully optimized, low magnification images revealed a more defective SL system. As shown in Fig. 5(a), the substrate/buffer interface is clearly visible, and it is not flat, although this lack of flatness does not apparently cause any defects in the SL layers. However, the ordered-alloy

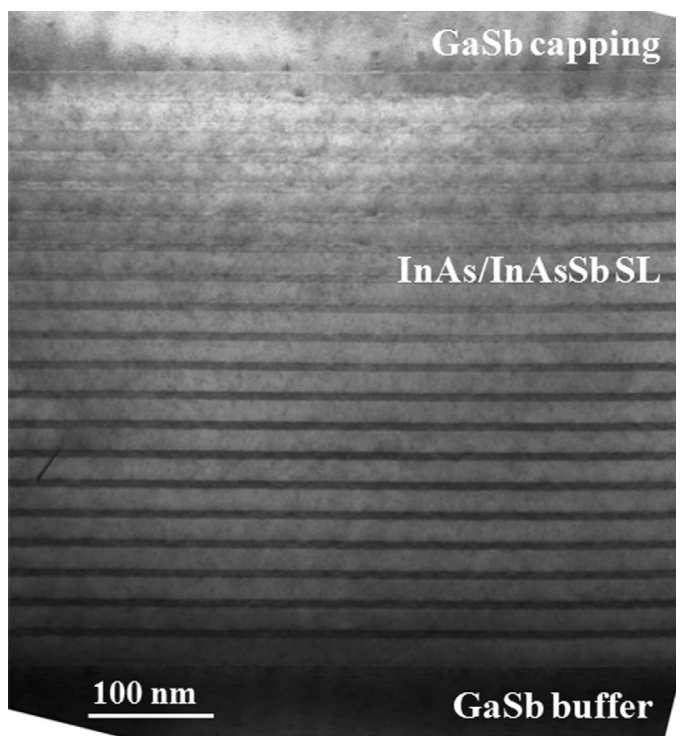

FIG. 3. Cross-sectional electron micrograph showing entire SL structure of Sample A, and confirming very low defect density.

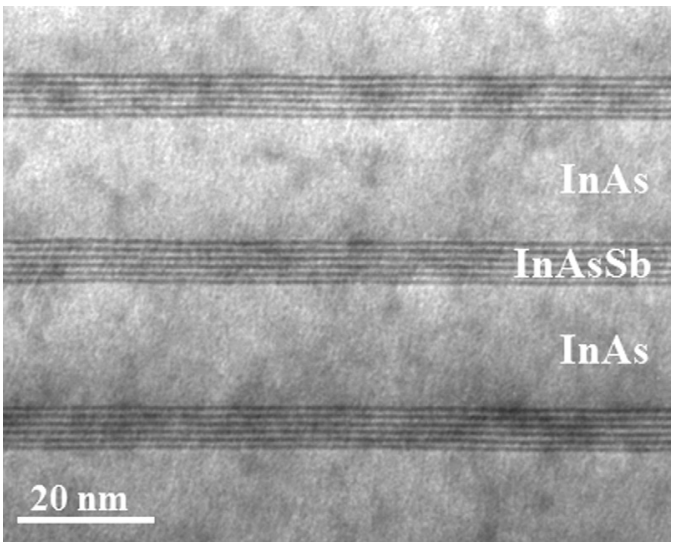

Fig. 4. Higher-magnification image clearly showing well-ordered $\operatorname{In}($ As) $\mathrm{Sb} / \mathrm{InAs}(\mathrm{Sb}) \mathrm{MQW}$ structure within the individual $\mathrm{InAs}_{1-\mathrm{x}} \mathrm{Sb}_{\mathrm{x}}$ layers of Sample A.

structure was only well-defined within the first $\operatorname{InAs}_{1-x} \mathrm{Sb}_{\mathrm{x}}$ layer and progressively disappeared within the later $\mathrm{InAs}_{1-\mathrm{x}} \mathrm{Sb}_{\mathrm{x}}$ layers, as shown in Fig. 5(b). Defective regions were visible within the SL structure that propagated upwards similar to the behavior of self-aligned quantum dots in lattice-mismatched systems, but opposite to the conventional domelike appearance. Most of these defects originated from the first SL layer, and are possibly due to the longer Sb shutter time used for this sample compared to Sample A. In
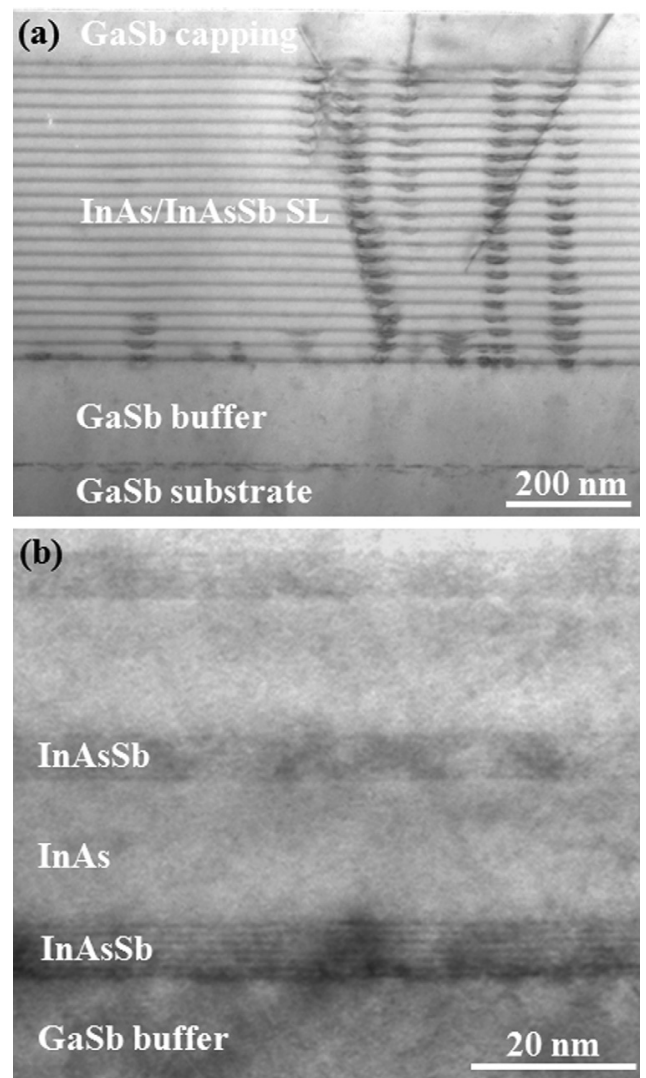

FIG. 5. (a) Low magnification image of Sample B showing typical defective region: (b) Higher-magnification image showing the presence of the $\operatorname{In}(\mathrm{As}) \mathrm{Sb} /$ InAs(Sb) MQW structure apparently only within the first InAs ${ }_{1-x} \mathrm{Sb}_{\mathrm{x}}$ layer. 


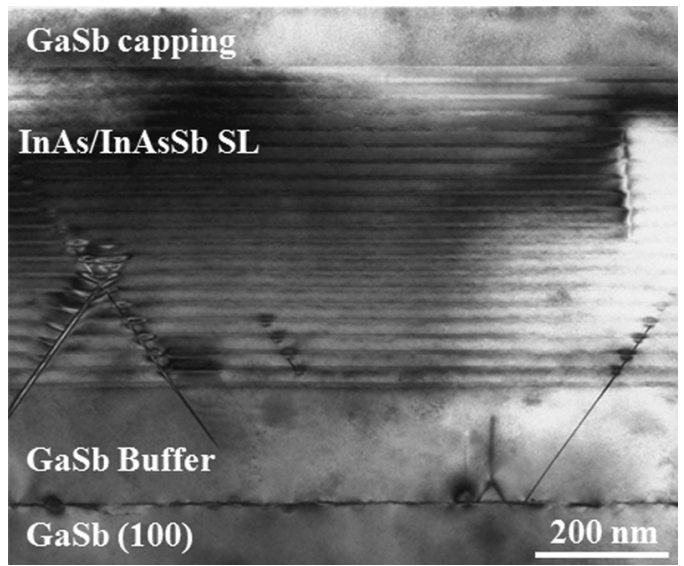

FIG. 6. Low magnification image of Sample C showing the entire structure.

addition, some extensive $\{111\}$-type stacking faults were observed propagating upwards through several SL periods to the top of the SL layer. The disappearance of the welldefined ordered-alloy structure within subsequent $\mathrm{InAs}_{1-\mathrm{x}} \mathrm{Sb}_{\mathrm{x}}$ layers is possibly due to intermixing of As and $\mathrm{Sb}$ atoms induced by the strain associated with propagating defects.

Low magnification images of Sample C, which was a random alloy SL that was again not grown under fully optimized conditions, revealed the entire structure including the $\mathrm{GaSb}$ (001) substrate and buffer layer, 20-period SL layers, and the GaSb capping layer, as shown in Fig. 6. Growth defects, such as $\{111\}$-type stacking faults, are clearly visible. Most of these defects originated at the substrate/buffer interface, but some originated in the middle of the buffer layer, and many were present within the SL layers.

In the case of Sample D, cross-section electron micrographs typically showed no evidence of any defects across the entire field of view and demonstrated that excellent crystalline quality of the $\mathrm{InAs} / \mathrm{InAs} \mathrm{s}_{0.71} \mathrm{Sb}_{0.29}$ SL could be achieved. The entire structure showing 20 well-defined SL periods is visible in Fig. 7. The substrate/buffer interface was again observed not to be flat, but no defects in the buffer

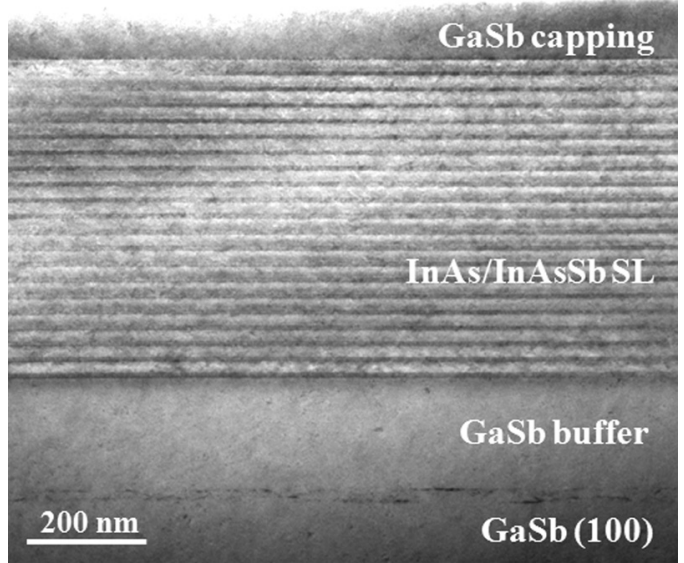

Fig. 7. Cross-sectional electron micrograph of Sample D demonstrating the well-defined and defect-free $\mathrm{InAs} / \mathrm{InAs}_{0.71} \mathrm{Sb}_{0.29} \mathrm{SL}$ region.
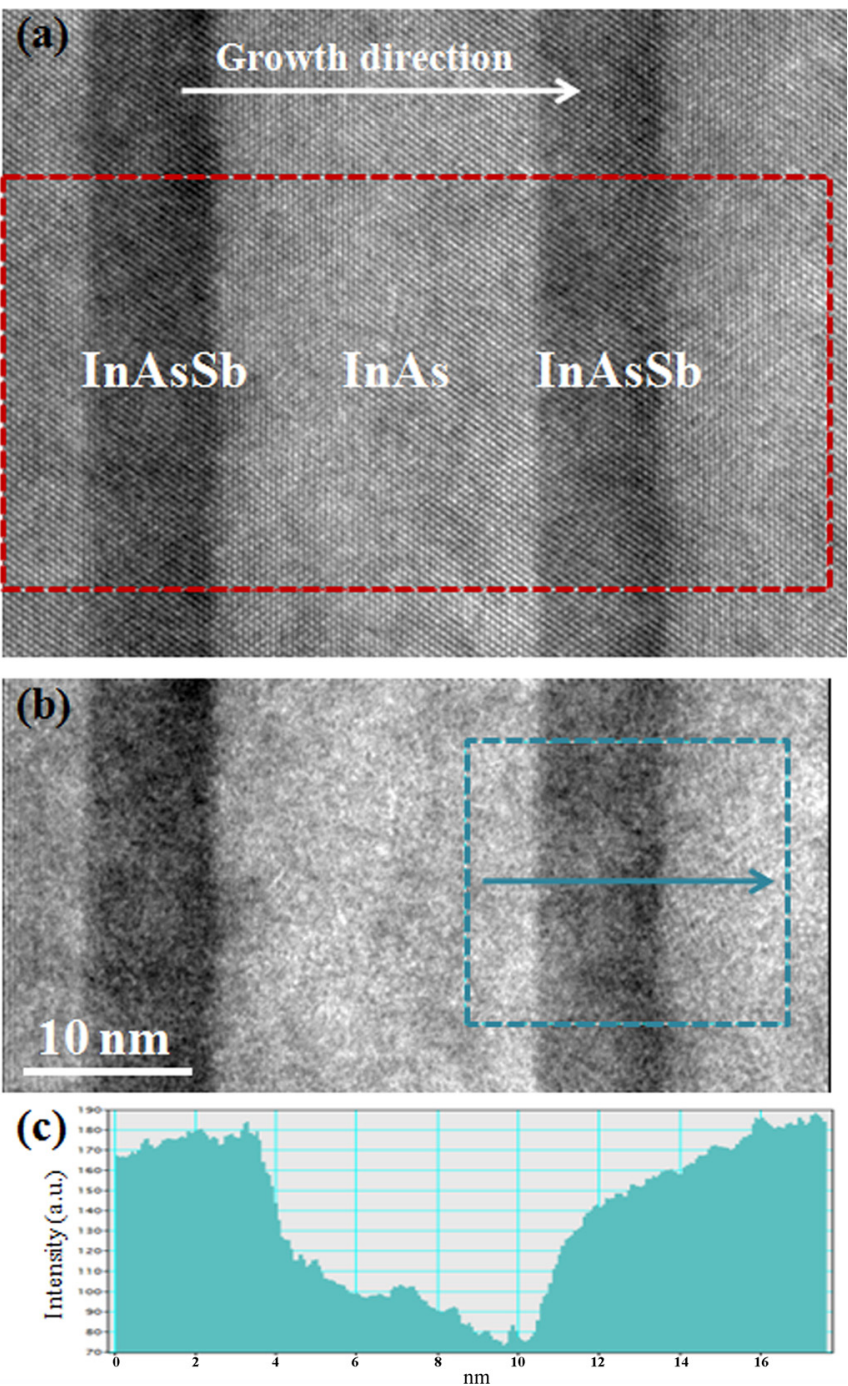

FIG. 8. (Color online) (a) High-resolution lattice image showing individual InAs and $\mathrm{InAs}_{0.71} \mathrm{Sb}_{0.29}$ layers for sample D; (b) Filtered image revealing different interface abruptness between layers, which is attributed to segregation of the $\mathrm{Sb}$ surfactant during growth; (c) Line profile average across both InAs-on-InAsSb and InAsSb-on-InAs interfaces, as indicated by blue dashed area boxed above, showing the differences in interface abruptness.

layer have been caused by this lack of flatness. (It is worth noting here that such homoepitaxial interfaces are not always visible in the TEM images of samples grown under optimal conditions when there is complete desorption of the surface oxide layer present on the GaSb substrate surface.)

High-resolution lattice images of Sample D, such as Fig. 8(a), clearly show the individual InAsSb and InAs layers. As confirmed by the Fourier-filtered image of the indicated area shown in Fig. 8(b), it is also apparent that the interfaces of the $\operatorname{InAs}_{0.71} \mathrm{Sb}_{0.29}$ layers grown on InAs are more abrupt than those of InAs layers grown on $\operatorname{InAs}_{0.71} \mathrm{Sb}_{0.29}$. Figure 8(c) is a line profile averaging across both InAs-on-InAsSb and InAsSb-on-InAs interfaces, as indicated by the blue dashed area boxed on Fig. 8(b). It is clear that the intensity drops rapidly at the InAsSb-on-InAs interface, while the intensity increases much more slowly at the InAs-on-InAsSb interface. This interface asymmetry in the SL layers is most 
likely related to $\mathrm{Sb}$ segregation, whereby some unintentional $\mathrm{Sb}$ is initially incorporated into the InAs layers during growth, as reported previously. ${ }^{20,28}$

\section{SUMMARY}

The structural properties of strain-balanced InAs/ $\mathrm{InAs}_{1-\mathrm{x}} \mathrm{Sb}_{\mathrm{x}} \mathrm{SLs}$ grown by MBE on GaSb (001) substrates, have been studied using XRD and TEM. Excellent atomicscale structural quality of the InAs/InAs ${ }_{1-x} \mathrm{Sb}_{\mathrm{x}}$ SLs has been demonstrated by TEM. Well-defined ordered-alloy In(As)Sb/ InAs(Sb) MQW layers within individual InAs ${ }_{1-x} \mathrm{Sb}_{\mathrm{x}}$ layers, were observed for samples grown by modulated MBE. However, the ordering disappeared when defects propagating through the SL layers appeared during growth. For samples grown by conventional MBE, high-resolution images revealed that interfaces for $\mathrm{InAs}_{1-\mathrm{x}} \mathrm{Sb}_{\mathrm{x}}$ grown on InAs layers were sharper than for InAs grown on $\operatorname{InAs}_{1-\mathrm{x}} \mathrm{Sb}_{\mathrm{x}}$ layers, most likely due to some $\mathrm{Sb}$ surfactant segregation effect which warrants further investigation. Overall, the microstructural results are highly promising for the future growth of InAs/InAs ${ }_{1-\mathrm{x}} \mathrm{Sb}_{\mathrm{x}} \mathrm{SLs}$ designed for operation at specific wavelengths.

\section{ACKNOWLEDGMENTS}

The work at ASU was primarily supported by the MURI Grant No. W911NF-10-1-0524 administered by U.S. Army Research Office, and monitored by William W. Clark. The authors gratefully acknowledge the use of facilities in the John M. Cowley Center for High Resolution Electron Microscopy at Arizona State University.

${ }^{1}$ G. A. Sai-Halasz, R. Tsu, and L. Esaki, Appl. Phys. Lett. 30, 651 (1977).

${ }^{2}$ D. L. Smith, T. C. McGill, and J. N. Schulman, Appl. Phys. Lett. 43, 180 (1983).

${ }^{3}$ D. L. Smith and C. Mailhiot, J. Appl. Phys. 62, 2545 (1987).

${ }^{4}$ D. N. Talwar and J. P. Loehr, Phys. Rev. B 49, 10345 (1994).
${ }^{5}$ C. H. Grein, P. M. Young, and H. Ehrenreich, Appl. Phys. Lett. 61, 2905 (1992).

${ }^{6}$ D. H. Chow, R. H. Miles, T. C. Hasenberg, A. R. Kost, Y.-H. Zhang, H. L. Dunlap, and L. West, Appl. Phys. Lett. 67, 3700 (1995).

${ }^{7}$ J. L. Johnson, L. A. Samoska, A. C. Gossard, J. L. Merz, M. D. Jack, G. R. Chapman, B. A. Baumgratz, K. Kosai, and S. M. Johnson, J. Appl. Phys. 80, 1116 (1996).

${ }^{8}$ H. Mohseni, M. Razeghi, G. J. Brown, and Y. S. Park, Appl. Phys. Lett. 78, 2107 (2001).

${ }^{9}$ A. Hood, D. Hoffman, B.-M. Nguyen, P.-Y. Delaunay, E. Michel, and M. Razeghi, Appl. Phys. Lett. 89, 093506 (2006).

${ }^{10}$ G. C. Osbourn, J. Vac. Sci. Technol. B 2, 176 (1984).

${ }^{11}$ Y.-H. Zhang, Appl. Phys. Lett. 66, 118 (1995).

${ }^{12}$ D. Lackner, O. J. Pitts, M. Steger, A. Yang, M. L. W. Thewalt, and S. P. Watkins, Appl. Phys. Lett. 95, 081906 (2009).

${ }^{13}$ Y. Huang, J.-H. Ryou, R. D. Dupuis, V. R. D'Costa, E. H. Steenbergen, J. Fan, Y.-H. Zhang, A. Petschke, M. Mandl, and S.-L. Chuang, J. Cryst. Growth 314, 92 (2011).

${ }^{14}$ E. H. Steenbergen, Y. Huang, J.-H. Ryou, L. Ouyang, J.-J. Li, D. J. Smith, R. D. Dupuis, and Y.-H. Zhang, Appl. Phys. Lett. 99, 071111 (2011).

${ }^{15}$ W. Walukiewicz, Mater. Res. Soc. Symp. Proc. 148, 137 (1989).

${ }^{16} \mathrm{C}$. H. Grein, M. E. Flatte, and H. Ehrenreich, Proceedings on the Third International Symposium on Long Wavelength Infrared Detectors and Arrays: Physics and Applications III, Chicago, IL, 8-13 October 1995 (Electrochemical Society, Pennington, 1995), p. 211.

${ }^{17}$ E. H. Steenbergen, B. C. Connelly, G. D. Metcalfe, H. Shen, M. Wraback, D. Lubyshev, Y. Qiu, J. M. Fastenau, A. W. K. Liu, S. Elhamri, O. O. Cellek, and Y.-H. Zhang, Appl. Phys. Lett. (in press).

${ }^{18}$ Y.-H. Zhang, J. Cryst. Growth 150, 838 (1995).

${ }^{19}$ Y.-H. Zhang and D. H. Chow, Appl. Phys. Lett. 65, 3239 (1994).

${ }^{20}$ A. Y. Lew, E. T. Yu, and Y.-H. Zhang, J. Vac. Sci. Technol. B 14, 2940 (1996).

${ }^{21}$ Y.-H. Zhang, A. Lew, E. Yu, and Y. Chen, J. Cryst. Growth 175, 833 (1997).

${ }^{22}$ E. Hall, H. Kroemer, and L. A. Coldren, J. Cryst. Growth 203, 447 (1999).

${ }^{23}$ R. Kaspi and G. P. Donati, J. Cryst. Growth 251, 515 (2003).

${ }^{24}$ K. Muraki, S. Fukatsu, Y. Shiraki, and R. Ito, Appl. Phys. Lett. 61, 557 (1992).

${ }^{25}$ P. M. Young and H. Ehrenreich, Appl. Phys. Lett. 61, 1069 (1992).

${ }^{26}$ E. H. Steenbergen, K. Nunna, L. Ouyang, B. Ullrich, D. L. Huffaker, D. J. Smith, and Y.-H. Zhang, J. Vac. Sci. Technol. B (to be published).

${ }^{27}$ C. Z. Wang, D. J. Smith, S. Tobin, T. Parodos, J. Zhao, Y. Chang, and S. Sivananthan, J. Vac. Sci. Technol. A 24, 995 (2006).

${ }^{28}$ J. Steinshnider, J. Harper, M. Weimer, C.-H. Lin, S. S. Pei, and D. H. Chow, Phys. Rev. Lett. 85, 4562 (2000). 